\title{
Dificuldades no aleitamento materno na maternidade da fundação santa casa de misericórdia do Pará e o apoio do banco de leite
}

\author{
Difficulties in maternal breastfeeding in the maternity of the holy foundation casa de \\ misericórdia do Pará and the support of bank of milk
}
Dificultades en el enmienda materna en la maternidad de la fundación santa casa de misericordia del Pará y el apoyo del banco de leche

Yuri José Almeida da Silva ${ }^{1 *}$, Ana Claudia Damasceno ${ }^{1}$, Carla Daniele Nascimento Pontes², Mateus Queiroz Correa1, Hugo Henrique Ramos Gurjão1, Imaikon Gomes de Lima1', Felipe Bezerra da Costa ${ }^{1}$, Rudá Castilho de Carvalho ${ }^{1}$, Rafael Sizo Nascimento ${ }^{1}$.

\section{RESUMO}

OBJETIVO: Avaliar as dificuldades na amamentação em 50 puérperas na Maternidade da Fundação Santa Casa de Misericórdia e o apoio recebido do Banco de Leite. METODOLOGIA: Trata-se de um estudo Descritivo, observacional, transversal. O trabalho foi realizado na Maternidade da Fundação Santa casa de Misericórdia do Pará nas enfermarias de puerpério. RESULTADOS: A principal dificuldade no aleitamento materno encontrada foi a não apojadura do leite, seguida de mamilo invertido bilateralmente, fissura nos mamilos e dificuldade na sucção. A idade média das puérperas foi de 25,54 anos; a maioria era proveniente de zona urbana e residente na capital paraense, cursava o ensino médio, tinha companheiro, não planejara a presente gravidez, era primigesta, realizara pré-natal com 6 ou mais consultas e em algum momento fora conversado sobre amamentação. A maioria também teve seus filhos por via cesariana, transcorrendo o parto sem problemas, sendo a média de horas de vida dos neonatos no momento da pesquisa de 36,64 horas. Todas as pacientes entrevistadas pretendiam amamentar seus filhos da presente gestão, sendo que a maioria delas sabe da importância do aleitamento materno e acredita que ele pode se dar em regime exclusivo por no mínimo 6 meses. Quase a totalidade das puérperas já tinham recebido auxílio do banco de leite no momento da pesquisa e a maior parte delas se sentiu segura após tal suporte. CONCLUSÃO: A amamentação é um processo importantíssimo no desenvolvimento mãe-bebê e identificar o que mais dificulta esse processo é fundamental para uma adequada assistência e nesse sentido os bancos de leite entram como principal trunfo nos hospitais de referência como o do estudo.

Palavras chave: Aleitamento, Banco de Leite, Dificuldades.

\begin{abstract}
OBJECTIVE: To evaluate the difficulties in breastfeeding in 50 puerperas at the Santa Casa de Misericórdia Maternity Hospital and the support received from the Milk Bank. METHODOLOGY: This is a descriptive, observational, cross-sectional study. The work was carried out at the Maternity of the Holy House of Misericórdia Pará Foundation in the puerperal wards. RESULTS: The main difficulty in breastfeeding was the non-lactation of milk, followed by inverted nipple bilaterally, fissure in the nipples and difficulty in sucking. The mean age of postpartum women was 25.54 years; the majority came from an urban area and lived in the capital of Pará, had attended high school, had a partner, had not planned the present pregnancy, was a primigravida, had performed prenatal care with 6 or more consultations and had at some point been talked
\end{abstract}

${ }^{1}$ Universidade Federal do Pará - UFPA * E-mail: yurisilva20@hotmail.com

${ }^{2}$ Fundação Santa Casa de Misericórdia do Pará 
about breastfeeding. The majority had also had their babies by cesarean section, delivering the childbirth without problems, with the average hours of life of the neonates at the time of the research of 36.64 hours. All of the patients interviewed intend to breastfeed their children from this management, most of whom know the importance of breastfeeding and believe that it can be given exclusively for at least 6 months. Almost all of the puerperae had already been assisted by the milk bank at the time of the research and most of them felt safe after such support. CONCLUSION: Breastfeeding is a very important process in the development of mother and baby and identifying what makes this process more difficult is essential for adequate care. In this sense, milk banks are the main asset in reference hospitals such as the study.

Keywords: Breastfeeding, Milk Bank, Difficulties.

\section{RESUMEN}

OBJETIVO: Evaluar las dificultades en la lactancia en 50 puérperas en la Maternidad de la Fundación Santa Casa de Misericordia y el apoyo recibido del Banco de Leche. METODOLOGÍA: Se trata de un estudio descriptivo, observacional, transversal. El trabajo fue realizado en la Maternidad de la Fundación Santa casa de Misericordia del Pará en las enfermerías de puerperio. RESULTADOS: La principal dificultad en la lactancia materna encontrada fue la no apoya de la leche, seguida de pezón invertido bilateralmente, fisura en los pezones y dificultad en la succión. La edad media de las puérperas fue de 25,54 años; la mayoría provenía de zona urbana y residente en la capital paraense, cursaba la enseñanza media, tenía compañero, no planificó el presente embarazo, era primigesta, realizaba prenatal con 6 o más consultas y en algún momento fuera conversado sobre lactancia. La mayoría también había tenido a sus hijos por vía cesárea, transcurriendo el parto sin problemas, siendo la media de horas de vida de los recién nacidos en el momento de la encuesta de 36,64 horas. Todas las pacientes entrevistadas pretendían amamantar a sus hijos de la presente gestión, siendo que la mayoría de ellas saben de la importancia de la lactancia materna y cree que puede darse en régimen exclusivo por lo menos 6 meses. Casi la totalidad de las puérperas ya habían recibido ayuda del banco de leche en el momento de la investigación y la mayor parte de ellas se sintió segura después de tal soporte. CONCLUSIÓN: La lactancia materna es un proceso importantísimo en el desarrollo madrebebé e identificar lo que más dificulta ese proceso es fundamental para una adecuada asistencia y en ese sentido los bancos de leche entran como principal baza en los hospitales de referencia como el del estudio.

Palabras claves: Lactancia, Banco de Leche, Dificultades.

\section{INTROUÇÃO}

A amamentação é uma fase fundamental para o crescimento e desenvolvimento saudáveis na vida de todo ser humano. Este processo não depende apenas do instinto para se manter, sendo então indispensável a participação de outras pessoas como fonte de obtenção de aprendizado relacionado à amamentação, como mulheres mais experientes da família ou mesmo membros da vizinhança, além dos profissionais de saúde que atenderam essa paciente no decorrer do processo de gestação. Contudo, com a mudança do padrão familiar extensivo para o nuclear, e a consequente diminuição da participação direta da família no apoio às mães que iniciam a amamentação, a vulnerabilidade às dificuldades neste processo é consequência dessa menor habilidade em realiza-lo. (GIUGLIANE, 2004).

O aleitamento materno vai além de um simples mecanismo de aquisição de nutrientes que satisfazem as necessidades metabólicas de um ser em crescimento e desenvolvimento, envolve aspectos emocionais de ambos (mãe e bebê), fisiológicos, cognitivos, econômicos e sociais. Neste sentido o aleitamento materno se constitui como um tema de interesse público, tanto no que tange aos seus benefícios, já amplamente difundidos, quanto nos aspectos que podem comprometer seu sucesso. Embora seja um processo natural ele pode não ser encarado com facilidade por algumas mulheres, tendo em vista que não depende apenas de 
condições clínicas e anatômicas, mas emocionais, educacionais, culturais, históricas e subjetivas de cada indivíduo (SILVA e GUEDES, 2013).

O leite materno é um alimento completo que apresenta as características ideais para satisfazer as necessidades nutricionais da criança nos primeiros meses de vida, sua oferta deve ser estimulada visando diminuir as intercorrências na saúde da criança oriundas de uma alimentação inadequada. Além do benefício de ser um alimento de alto valor nutritivo o leite materno também constitui um importante aliado na prevenção de doenças carenciais como a anemia ferropriva, melhora da imunidade através do compartilhamento de anticorpos da mãe com o filho e promoção da saúde psíquica e física de ambas as partes. As taxas de mortalidade infantil podem diminuir com um aleitamento materno eficaz, sendo o aleitamento materno "a estratégia isolada que mais previne mortes infantis" (BRASIL, 2009, p. 17).

Contudo, mesmo com todos os benefícios associados ao aleitamento materno, alcançar as taxas recomendadas pela Organização Mundial da Saúde ainda é um grande desafio. Segundo pesquisa realizada pelo Ministério da Saúde para avaliar a prevalência de aleitamento materno nas capitais brasileiras e Distrito Federal, a prevalência de Aleitamento Materno Exclusivo (AME) foi de $41,0 \%$ no conjunto das mesmas, sendo Belém/PA a capital com maior prevalência - 56,1\% (Brasil, 2009). Estes números são ainda menos animadores quando se considera o número médio de dias de AME no Brasil que era de 54,1 em 2008 (data da última pesquisa), o que está aquém do preconizado pela OMS que é de 180 dias (WHO, 2001).

Durante o processo de amamentação surgem dificuldades que prejudicam uma boa prática do AME por parte da mãe, o que pode estimular o desmame precoce ou levar a introdução de alimentos menos indicados aos neonatos e lactentes. Algumas dificuldades são por parte da mãe como retorno precoce ao trabalho, infecções por vírus HIV, depressão pós-parto, mastite, fissuras, uso de drogas, entre outras coisas. Além disso, outras dificuldades são por parte do bebê como dificuldade na pega, por exemplo. Neste sentido, ao se verem frente a tais intemperes algumas mães simplesmente substituem o leite materno por outras fontes de leite como o leite de vaca, expondo o bebê ao risco de desenvolver alergias, alterações do trânsito intestinal e menor biodisponibilidade de ferro, sendo o leite de vaca considerado um fator de risco independente para o desenvolvimento de anemia carencial ferropriva (MOY RJ, 2006; CAETANO, 2010).

A duração do aleitamento materno também pode sofre influência das dificuldades vividas neste processo. Segundo estudo realizado em um hospital municipal de São Paulo que atende usuários do Sistema Único de Saúde (SUS), as mães que apresentaram alguma dificuldade na amamentação tiveram, em média, menor tempo de aleitamento exclusivo (ROCCI, FERNANDES, 2014).

Com o objetivo de reduzir a mortalidade infantil e incentivar o aleitamento materno algumas estratégias se mostram bem promissoras e são as principais iniciativas do Ministério da Saúde, como os Bancos de Leite Humano, presentes em várias cidades do Brasil. No Pará existe, desde 1987, o Banco de Leite Humano da Santa Casa, que é um dos maiores do país. Em 2013 este banco de leite, segundo relatório da instituição, atendeu cerca de 900 bebês internados na Santa Casa do Pará, sendo os recém-nascidos prematuros os principais beneficiados. A instituição trabalha desde a coleta até a distribuição do leite, passando pela preparação deste através do processo de pasteurização e armazenamento adequado feito em potes de vidro.

Segundo informações dispostas no site da Rede Brasileira de Bancos de Leite Humano esta tem objetivos: promover, proteger e apoiar o Aleitamento Materno; coletar e distribuir leite humano de qualidade certificada; contribuir para a redução da mortalidade infantil; somar esforços ao Pacto Nacional pela Redução da Mortalidade Materna e Neonatal. Portanto, este trabalho tem como objetivo avaliar as dificuldades na amamentação em 50 puérperas na Maternidade da Fundação Santa Casa de Misericórdia e o apoio recebido do Banco de Leite.

\section{METODOLOGIA}

Trata-se de um estudo Descritivo, observacional, transversal. O trabalho foi realizado na Maternidade da Fundação Santa casa de Misericórdia do Pará nas enfermarias de puerpério, que funcionam na Fundação 
Santa Casa de Misericórdia do Pará. A qual é referência para gestação de risco; certificada como Hospital Amigo da Criança por incentivar o aleitamento materno; dispõe do Banco de Leite Humano João Aprígio Guerra de Almeida que dentre as suas funções também é acionado em caso de dificuldades observadas no aleitamento materno, para identificar qual é a dificuldade para que seu profissional adequadamente treinado atue oferecendo apoio para que a dificuldade seja superada.

Foram selecionadas 50 puérperas que alegaram apresentar alguma dificuldade na amamentação e que concordaram em participar da pesquisa assinando o Termo de Consentimento Livre e Esclarecido (TCLE). Para as puérperas que tiveram idade menor que 18 anos foram incluídas na pesquisa aquelas que tiveram o TCLE assinado pelo responsável legal (pai ou mãe), e ainda assinaram o Termo de Assentimento Livre e Esclarecido.

Após ter sido aprovada a pesquisa pelo CEP da referida instituição com parecer de número 1.215.528, o pesquisador realizou visita diária (até conseguir entrevistar 50 puérperas que preencheram os critérios de inclusão e que tenham consentido participar da pesquisa) à maternidade da FSCMPA nas enfermarias de puerpério que funcionam em sistema de alojamento conjunto (ALCON) onde permaneceram juntos mãe (puérpera) e recém-nascido, lá o pesquisador/entrevistador se apresentou e perguntou se alguma mãe estava com dificuldades para amamentar, em seguida apresentou esclarecimento sobre a pesquisa que trata de dificuldades no aleitamento materno.

As voluntárias receberam um Termo de Consentimento Livre e Esclarecido (TCLE) , no qual constavam as informações acerca da pesquisa que fora realizada. Em caso de dificuldade na leitura do material as volutárias solicitaram que o pesquisador/entrevistador fizesse a leitura do TCLE em voz alta, de forma clara e objetiva. Após a compreensão dos procedimentos a serem realizados fora solicitado à paciente que assinasse o termo, caso ela concordasse e preeenchesse os critérios de inclusão, permitindo a realização da pesquisa com ela. A voluntária assinou duas vias do mesmo documento, ficando a voluntária de posse de uma das vias. Vencida esta etapa foi dado início à entrevista baseada na aplicação de um questionário com perguntas semi-estruturadas. O pesquisador/entrevistador fez as perguntas que constavam no questionário à volutária, as quais foram preenchidas no questionário pelo próprio entrevistador. Ao final, a entrevistada se verificou se as informações foram registradas segundo suas respostas visualizando o documento já preenchido.

A pesquisa esteve de acordo com os preceitos éticos da Declaração de Helsinque e do Código de Nuremberg, respeitando as normas de pesquisa envolvendo seres humanos RESOLUÇÃO №466, DE 12 DE DEZEMBRO DE 2012 do Conselho Nacional de Saúde, e o projeto elaborado de acordo com o previsto pela NORMA OPERACIONAL № 001/2013 do Conselho Nacional de Saúde e a coleta de dados se deu somente após aprovação do projeto de pesquisa pelo Comitê de Ética em Pesquisa da FSCMPA e autorização da Gerência de Pesquisa desta Instituição.

Os dados coletados na entrevista nas fichas individuais, foram registrados em planilhas confeccionadas com o software Microsoft $\Theta$ Office Exce/ $\AA^{\circledR 2010}$, onde foi construído um banco de dados. Foram elaboradas as estatísticas descritivas do estudo em tabelas e gráficos a partir do cálculo das frequências (variáveis categóricas) e das medidas de tendência central e de dispersão (médias e desvios-padrões das variáveis quantitativas). O nível de significância (alfa) adotado foi de 5\%.

Variáveis estudadas: Quantitativas: idade materna (em anos completos), tempo de vida do recém-nascido (horas ou dias de vida a partir de 3 dias), número de filhos anteriores, tempo de amamentação de filhos anteriores (em meses completos), número de consultas de pré-natal da gestação atual. Qualitativas: residência (interior do estado: zona rural ou urbana; capital); escolaridade; se tem companheiro; se planejou ou desejou a gravidez; realização ou não de pré-natal; abordagem sobre amamentação no pré-natal; insucesso na amamentação de filhos mais velhos; tipo de dificuldades na amamentação de filho anterior; se pretende amamentar; se sabe da importância da amamentação; qual a principal importância da amamentação segundo sua avaliação; quanto tempo acha que é possível o aleitamento materno exclusivo; dificuldade atual na amamentação; apoio do banco de leite; segurança após ter recebido apoio do banco de leite. 


\section{RESULTADOS}

A amostra estudada foi composta de 50 puérperas, com média de idade de 25,54 anos e sendo apenas 13 dessas puérperas menores de 21 anos.

Ao avaliar o local de residência das pacientes, dividiu-se a descrição segundo o local de residência (se capital ou interior) e zona (se urbana ou rural). Logo, observou-se que $80 \%$ das puérperas reside em zona urbana e $56 \%$ na capital paraense.

A análise do grau de escolaridade compreendeu a faixa entre o ensino fundamental e superior, avaliandoos se completo ou incompleto. Observou-se que $26 \%$ concluíram o ensino médio, $20 \%$ apresentou ensino fundamental incompleto e apenas $20 \%$ galgou até o ensino superior.

Também foi questionado às pacientes se as mesmas possuíam companheiro (namorado, noivo, esposo ou relação estável) e quanto ao planejamento daquela gestação. Constatou-se, então, que $80 \%$ das pacientes tinham companheiro e que somente $18 \%$ das gestacões foram planejadas.

Quanto aos antecedentes obstétricos, 33 pacientes (66\%) eram primigestas, 8 pacientes (16\%) secundigestas e 9 (18\%) multigestas (3 ou mais filhos). Quando questionadas sobre a realização do pré-natal da atual gestação $88 \%$ disse ter feito pré-natal e dessas $77,27 \%$ realizaram 6 ou mais consultas, com 8 pacientes dizendo ter realizado 8 consultas, 8 realizaram 10 consultas e 1 realizou 14 consultas. Ainda sobre as puérperas que realizaram pré-natal, $40,90 \%$ disseram que em nenhum momento dessas consultas foi conversado sobre amamentação (Tabela 1).

Tabela 1: Distribuição das Puérperas com dificuldades no aleitamento materno atendidas na FSCMPA, de acordo com a realização e o número de consultas pré-natais e a abordagem sobre amamentação em Belém/PA - 2016.
VARIÁVEIS
RESULTADOS

\section{REALIZOU PRÉ-NATAL DESTA GESTAÇÃO}

$\begin{array}{ll}\text { Sim } & 88 \% \\ \text { Não } & 12 \%\end{array}$

\section{ABORDAGEM SOBRE AMAMENTAÇÃO}

$\begin{array}{ll}\text { Sim } & 59,10 \% \\ \text { Não } & 40,90 \%\end{array}$

\section{№ DE CONSULTAS PRÉ-NATAIS DESTA GESTAÇÃO}
$<6$ consultas
$22,72 \%$
$>6$ consultas
$77,28 \%$

Fonte: Dados primários da pesquisa.

No que tange ao parto das pacientes participantes, $42 \%$ tiveram partos realizados por via natural (parto normal) e $58 \%$ cesariana; $90 \%$ não apresentaram nenhum tipo de problema e os outros $10 \%$ necessitaram de reanimação neonatal (Tabela 2). No momento da pesquisa os recém-nascidos tinham em média 36,64 horas de vida. 
Tabela 2: Distribuição das Puérperas com dificuldades no aleitamento materno atendidas na FSCMPA, de acordo com as características do parto em Belém/PA - 2016.

\section{VARIÁVEIS RESULTADO}

TIPO DE PARTO

$\begin{array}{cc}\text { Vaginal (normal) } & 42 \% \\ \text { Cesariana } & 58 \%\end{array}$

\section{PROBLEMA NO PARTO}

$\begin{array}{ll}\text { Sim } & 10 \% \\ \text { Não } & 90 \%\end{array}$

Fonte: Dados primários da pesquisa.

Todas as mães que participaram da pesquisa pretendiam amamentar seus filhos, mas apenas $64 \%$ sabiam da importância do aleitamento materno tanto para si mesma quanto para o neonato. Quando questionadas sobre até quando achavam ser necessário o Aleitamento Materno Exclusivo (AME) 12\% não soube responder, $10 \%$ achava ser por um período menor que 6 meses e $78 \%$ respondeu por 6 meses ou mais (Tabela 3).

Tabela 3: Distribuição das Puérperas com dificuldades no aleitamento materno atendidas na FSCMPA, segundo seus conhecimentos sobre a importância do aleitamento materno e o período de Aleitamento Materno Exclusivo (AME) em Belém/PA - 2016.

\begin{tabular}{ll}
\hline \multicolumn{1}{l}{ VARIÁVEIS } & RESULTADOS \\
\hline SABE DA IMPORTÂNCIA DO ALEITAMENTO MATERNO & \\
Sim & $64 \%$ \\
Não & $36 \%$ \\
OPNIÃO SOBRE O PERÍODO DE AME & \\
$<6$ meses & $10 \%$ \\
6 meses & $70 \%$ \\
$>6$ meses & $8 \%$ \\
Não soube responder & $12 \%$ \\
\hline
\end{tabular}

Fonte: Dados primários da pesquisa.

Quando analisadas as mães com filhos nascidos vivos de gestações anteriores (14 não primíparas, pois 3 das primigestas tiveram gemelares), $85,71 \%$ amamentaram seus outros filhos; destas, apenas 3 mães (25\%) prologaram o aleitamento até o segundo ano de vida dos seus filhos. Agora quando questionadas sobre o Aleitamento Materno Exclusivo (AME), 66,67\% cumpriram os 6 meses de AME, 8,33\% ultrapassaram este período e $25 \%$ estiveram aquém desta marca. Destas 14 pacientes com filhos mais velhos, $57,14 \%$ relataram 
dificuldades para amamentar anteriores à gestação em pesquisa, sendo 12,5\% por mastite bilateral, $12,5 \%$ por rachadura em um dos mamilos, $12,5 \%$ por mamilos invertidos bilateralmente, $25 \%$ por um dos mamilos plano e $37,5 \%$ por não apojadura do leite (Gráfico 1). Das 14,29\% mães que não amamentaram seus filhos anteriores $50 \%$ foi por conta de mamilo plano bilateralmente e os outros $50 \%$ por conta de mamilo invertido bilateralmente (Tabela 4).

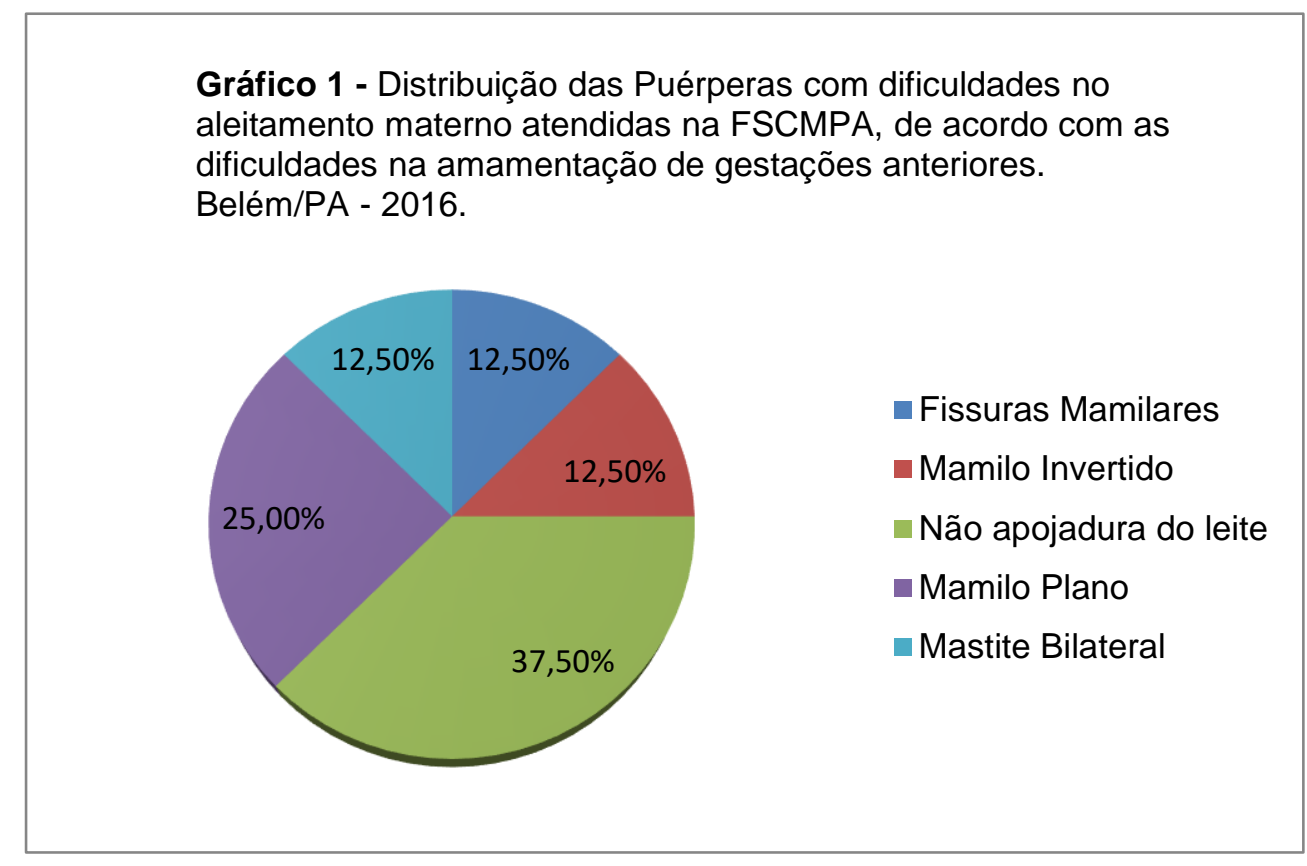

Fonte: Dados primários da pesquisa.

Tabela 4: Distribuição das Puérperas com dificuldades no aleitamento materno atendidas na FSCMPA, de acordo com características de gestações anteriores em Belém/PA - 2016.

\begin{tabular}{|c|c|}
\hline VARIÁVEIS & RESULTADO \\
\hline \multicolumn{2}{|l|}{ AMAMENTOU FILHOS ANTERIORES } \\
\hline Sim & $85,71 \%$ \\
\hline Não & $14,29 \%$ \\
\hline \multicolumn{2}{|c|}{$\begin{array}{l}\text { APRESENTOU DIFICULDADES NA AMAMENTAÇÃO DE } \\
\text { SEUS FILHOS ANTERIORES }\end{array}$} \\
\hline $\operatorname{Sim}$ & $57,15 \%$ \\
\hline Não & $42,85 \%$ \\
\hline \multicolumn{2}{|c|}{$\begin{array}{l}\text { POR QUANTO TEMPO AMAMENTOU SEUS OUTROS } \\
\text { FILHOS }\end{array}$} \\
\hline Até $1^{\circ}$ ano de vida & $50 \%$ \\
\hline Até $2^{\circ}$ ano de vida & $50 \%$ \\
\hline \multicolumn{2}{|c|}{ AME DOS FILHOS ANTERIORES POR QUANTO TEMPO } \\
\hline$<6$ meses & $25 \%$ \\
\hline 6 meses & $66,7 \%$ \\
\hline$>6$ meses & $8,3 \%$ \\
\hline
\end{tabular}

Fonte: Dados primários da pesquisa. 
A principal dificuldade no aleitamento materno encontrada nesta pesquisa foi a não apojadura do leite (28\%), pois aconteceu tanto de modo isolado quanto associado a outros tipos de dificuldade, seguida de mamilos invertidos bilateralmente (12\%), fissuras nos mamilos ( $8 \%$ ) e dificuldade de sucção $(8 \%)$. A pega inadequada também foi uma dificuldade bastante relatada, sobretudo associada a outras dificuldades (Gráfico 2).

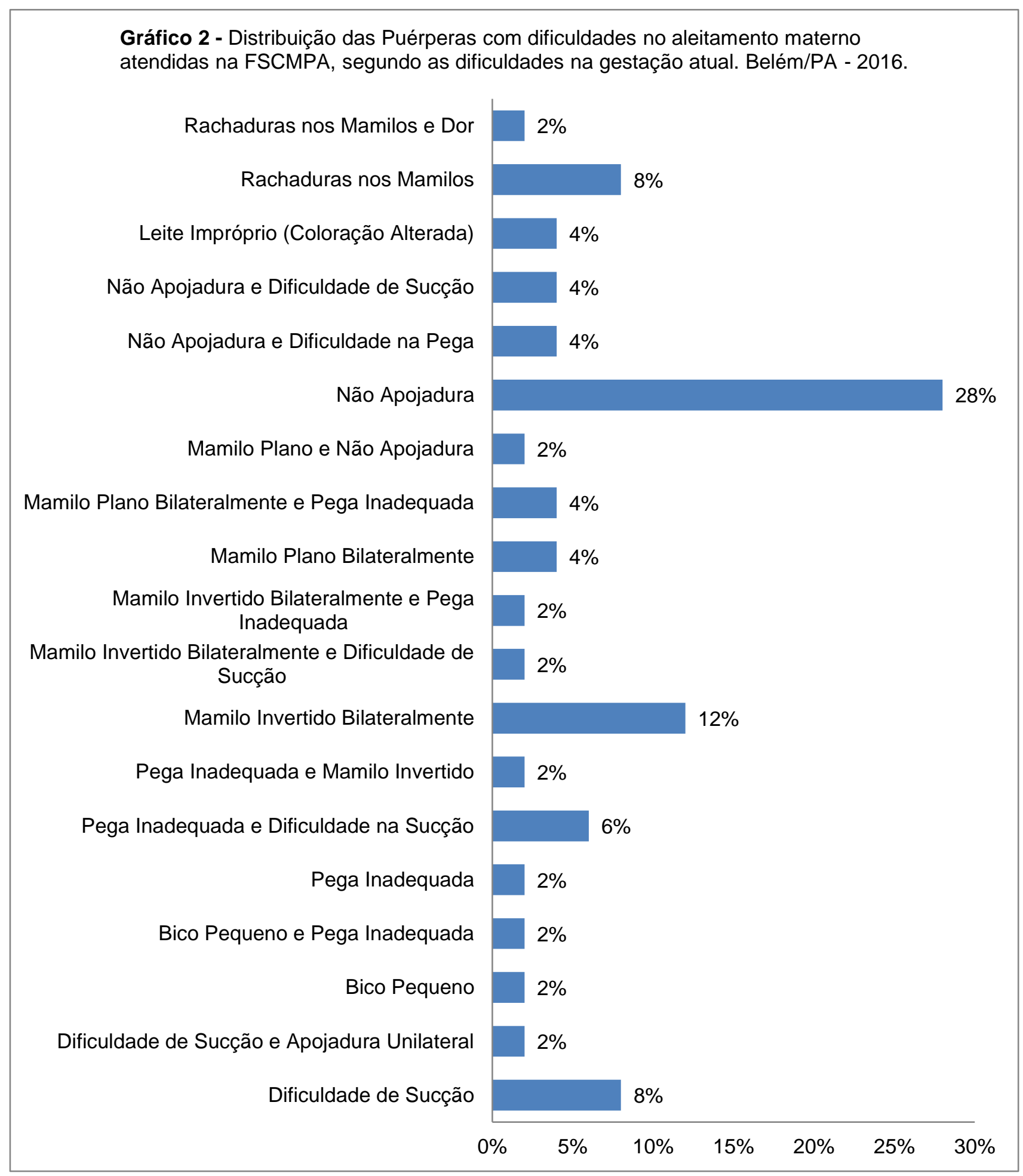

Fonte: Dados primários da pesquisa. 
No momento da pesquisa $96 \%$ das entrevistadas estava com dificuldade no processo de aleitamento materno, seguidas de $4 \%$ que já tinham enfrentado tais dificuldades. Do total das pacientes $16 \%$ não tinham recebido ajuda do banco de leite até o momento da pesquisa, contra $84 \%$ que já tinham recebido tal ajuda. Dentre as que já tinham recebido ajuda $9,52 \%$ receberam apenas orientação quanto à pega; $4,76 \%$ receberam apenas complemento ; $2,38 \%$ receberam orientação quanto à pega e quanto à ordenha manual; $7,14 \%$ receberam orientação quanto à pega e complemento; $19,04 \%$ receberam orientação quanto à ordenha manual e complemento; $52,38 \%$ orientações quanto à pega, quanto à ordenha manual e complemento; $4,76 \%$ apenas complemento e outras medidas de auxílio (Massagem para auxiliar na eversão dos mamilos) (Gráfico 3). Após o auxílio do banco de leite $85,71 \%$ se sentiu mais segura em relação ao processo de amamentação, contra $14,29 \%$ que ainda permaneceu insegura.

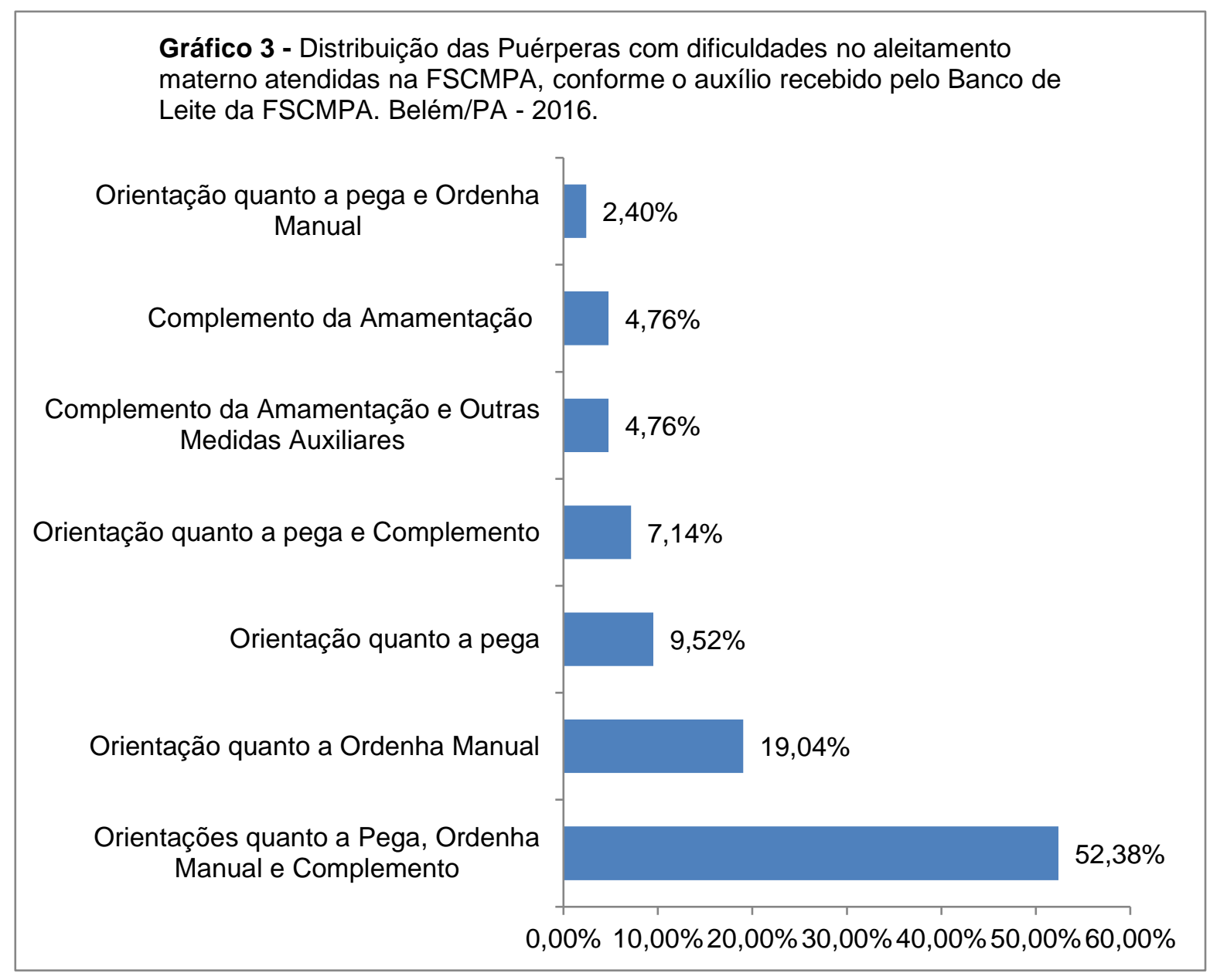

Fonte: Dados primários da pesquisa.

\section{DISCUSSÃO}

O aleitamento materno é um fenômeno natural, mas que precisa ser acompanhado afim de que seu sucesso seja garantido. O conhecimento dos detalhes que envolvem o processo de amamentação permite aos profissionais a ele ligados (médicos, enfermeiros, assistentes sociais, etc) uma melhor compreensão do binômio mãe-filho, de suas necessidades e seus medos, bem como da melhor forma de intervir em caso de alterações neste processo (VOLPINI e MOURA, 2005). Segundo Carvalho et al. (2013, p. 249) é importante que a equipe de saúde compartilhe os conhecimentos sobre o Aleitamento Materno, visando à continuidade deste processo e assim garantir um desenvolvimento satisfatório para o neonato e sua progenitora. Neste 
sentido, conhecer os detalhes deste binômio ultrapassa os limites do local de atuação da equipe de saúde, sendo fundamental saber as características sociais, econômicas e culturais da população ali assistida.

O perfil sociodemografico das nutrizes é um importante fator associado à prática do aleitamento materno e de como essas mães se importam com essa prática. Em pesquisa realizada por Fragoso e Fortes (2011) no Distrito Federal a idade e o nível de escolaridade das pacientes foram referidos como positivos relacionados à duração do aleitamento materno e a falta de apoio familiar com um fator negativo.

No presente estudo foi observado que a faixa etária das puérperas atendidas foi em média de 25,54 anos, faixa etária semelhante à encontrada por Fragozo e Fortes (2011) e Rocci e Fernandes (2014) nos trabalhos realizados em hospitais públicos de outras capitais. A idade é citada como um fator ligado ao desmame precoce, uma vez que as mães de menor idade apresentam maior frequência de dificuldade na amamentação e tendem a desmamar mais precocemente seus filhos por conta disso (LIMA; JAVORSKI; VASCONCELOS, 2011, p. 916). Em estudo realizado na Fundação Santa Casa de Misericórdia do Pará por Marques et al (2008) com mães adolescentes, aproximadamente $40 \%$ das entrevistadas (que estava na faixa etária de 15-19 anos) apresentou algum tipo de dificuldade no decorrer da amamentação de seus filhos, o que está acima do encontrado em nosso estudo para esta faixa etária, revelando a melhoria assistencial oferecida às adolescentes do presente estudo e a consequente diminuição de dificuldades.

A maioria das nutrizes tinha mais de 8 anos completos de escolaridade, nenhuma delas era analfabeta e $26 \%$ concluíram o ensino médio. Fragoso e Fortes (2011) também encontraram resultados semelhantes em seu estudo, diferindo apenas que $44,12 \%$ tinham segundo grau completo. A escolaridade é tida como fator de melhora da duração do aleitamento materno (ROIG et al, 2010).

O planejamento de uma gestação, o fato de ter companheiro, a realização e o número de consultas de pré-natal são variáveis marcantes na compreensão do processo de aleitamento materno e em como as dificuldades neste processo serão enfrentadas. No presente estudo $80 \%$ das puérperas tinha companheiro, algo próximo ao encontrado por Fragoso e Fortes (2011) no Distrito Federal (76,5\%) e um pouco maior ao encontrado por Rocci e Fernandes (2014) na cidade de São Paulo (70,3\%). Segundo Barbosa (2009) "A mãe que vive sem companheiro apresenta risco seis vezes maior de amamentar exclusivamente por menos tempo". Mesmo que o companheiro não seja o pai da criança ele é importante para o acolhimento e incentivo do aleitamento materno (FALEIROS et al, 2006).

O planejamento gestacional também está relacionado ao sucesso do aleitamento materno, pois permite um maior desejo em levar a gestação até o final e maior interesse por parte da mãe nos aspectos gestacionais. O estudo de Viellas et al (2014) afirma que puérperas residentes na região norte, com baixa escolaridade e sem companheiro tiveram menor cobertura pré-natal e início mais tardio de assistência, bem como as mães que não planejaram a gestação. No presente estudo foi observado que $88 \%$ das mães realizou o pré-natal, semelhante aos $85 \%$ encontrado por Oliveira, Patel e Fonseca (2004) em Feira de Santana/BA, mas aquém dos $100 \%$ referidos por Fragoso e Fortes (2011) no Distrito Federal. A realização do pré-natal interfere positivamente na autoeficácia da amamentação e redução de dificuldades neste processo segundo demonstra o estudo de Simões (2013). Contudo, os baixos números observados na amostra em estudo vão ao encontro ao exposto por Viellas et al (2014) ao afirmar que a cobertura pré-natal é menor em residentes nas regiões Norte e Nordeste.

No que tange ao número de consultas o Ministério da Saúde (BRASIL, 2012) recomenda o número mínimo de 6 consultas de pré-natal com a realização de consultas mensalmente para gestações até 28 semanas, quinzenalmente para gestações entre 28 e 36 semanas e semanalmente entre a $36^{\mathrm{a}}$ e $41^{\underline{a}}$ semana. Em estudo realizado com 151 mães adolescentes em um hospital público de Belém por Marques et al (2008) 31,12\% delas realizou menos de 6 consultas de pré-natal, percentual maior ao encontrado no presente estudo (22,72\%), mas ambos discrepantes em relação aos 73,53\% referidos por Fragoso e Fortes (2011) para mães com menos de 6 consultas de pré-natal. A consulta pré-natal é o ambiente propício para auxiliar a nutriz no aperfeiçoamento da amamentação pensando na prevenção de problemas mamários (FRAGOSO, FORTES, 2011; CREMONESE, et al, 2010). Com menos consultas de pré-natal menor é a chance de a paciente receber 
orientações sobre amamentação. E neste ponto é fundamental destacar o diferencial de um profissional capacitado na área de aleitamento materno, pois sem o devido treinamento da equipe de saúde as orientações quanto a este processo podem não ser ofertadas.

O estudo de Fragoso e Fortes (2011) realizado em um hospital público do Distrito Federal em 2010 destaca que $35,29 \%$ não recebera orientações sobre o aleitamento materno durante o pré-natal, algo próximo ao observado na amostra avaliada no presente estudo no qual $40,90 \%$ das puérperas não receberam orientação sobre amamentação durante seu pré-natal. Isto permite inferir a melhora na capacitação e valorização do tema por parte dos profissionais envolvidos no pré-natal com o passar dos anos, mas que ainda precisa avançar e ser mais homogêneo entre as regiões do Brasil.

Quando se relaciona as condições perinatais e as dificuldades no processo de aleitamento encontramos evidências na literatura que reforçam o encontrado neste trabalho. O estudo de Fragoso e Fortes (2011) expõem que $58,82 \%$ das entrevistadas teve parto tipo cesárea, percentual semelhante ao encontrado no presente estudo (58\%), mas ambos abaixo do observado por Simões (2013) que foi de $66 \%$ em estudo realizado com puérperas de um hospital no Distrito Federal. Em ambos os estudos vemos o parto cesáreo como fator que dificulta o aleitamento materno, seja por conta da dor e/ou efeito pós-anestésico ou mesmo pela imaturidade placentária ao se submeter à mãe a um parto eletivo sem sua indução natural, o que prejudica a produção do hormônio lactogênico placentário e consequentemente a apojadura do leite. Estas dificuldades podem influenciar o tipo de assistência recebida pela mãe, como mostra o estudo de Meirelles et al (2008) ao expor maior prevalência do uso de suplementos em bebês nascidos de parto cesáreo.

Os antecedentes obstétricos também estão relacionados às dificuldades no aleitamento materno, desde o número de filhos anteriores, se teve dificuldades na amamentação e o tempo de aleitamento do mesmo. $\mathrm{Na}$ amostra avaliada foi observado que $66 \%$ estavam em sua primeira gestação e que não tinham experiência prévia com amamentação. Porém, segundo Vieira et al (2010), a experiência com filhos anteriores não garante a amamentação dos filhos seguintes, pois de uma nova gestação provém um novo contexto para 0 aleitamento a ser realizado. Logo, interesse que o número de filhos, por si só, não garante a eficácia da amamentação de um novo bebê.

Os trabalhos de Junges (2010) e Oliveira e Marques (2011) discordam do que foi apontado por Vieira et al (2010) ao relatarem que uma amamentação bem sucedida em filhos anteriores é um fator predisponente e motivador para amamentar um novo bebê. Quanto às mães que apresentaram dificuldades no aleitamento nas outras gestações da amostra coletada $100 \%$ delas pretendia amamentar seus bebês da gestação em questão, mostrando a intenção de superar as dificuldades que outrora se interpuseram na vivência em amamentar. "Muitas puérperas mesmo relatando essas situações como obstáculos para o aleitamento, acabam superando-as por acreditar que o aleitamento é um evento que deve ser vivenciado pela mulher de maneira naturalizada e instintiva" (JUNGES et al, 2010, p. 346). O tempo de aleitamento materno de filhos anteriores, quer seja ele exclusivo ou complementar, e a boa experiência neste processo estão relacionados à intenção de amamentar o novo filho, interferindo positivamente nesta decisão (VIEIRA et al., 2010, p. 442).

O fato de as mães terem a intenção de amamentar seus filhos, independente das dificuldades, já foi observada em outros estudos, como o de Junges et al (2010) e Simões (2013). Isto pode ser relacionado ao aspecto natural e instintivo da amamentação como forma de prover nutrientes para um ser em formação, mas principalmente com a importância dada ao leite materno pelas nutrizes. O conhecimento dos benefícios do aleitamento materno, tanto para o bebê quanto para a mãe, relaciona-se positivamente com a vontade de amamentar, mesmo em caso de dificuldades. Junges et al (2010) observou em seu estudo com puérperas de Santa Maria/RS que mesmo em caso de dificuldades no aleitamento materno as mães, ao saberem da importância do seu leite para o bebê, motivaram-se em sanar as dificuldades (quer seja com a ajuda de um profissional de saúde ou de membros da família) para amamentar ao invés de substituir o leite por completo ou introduzir outros alimentos. Neste ponto o profissional de saúde é um agente indispensável para a disseminação do conhecimento, como afirma Santiago e Santiago (2014). Os enfermeiros, médicos e os demais profissionais da saúde envolvidos nos cuidados da díade mãe/bebê, devem auxiliar na prevenção das dificuldades no aleitamento materno ajudando as mães, sobretudo as primigestas, a compreender as 
peculiaridades e os obstáculos mais comuns deste processo. O estudo de Barreto, Silva e Christoffel (2009) afirma que "mães que receberam orientações sobre amamentação durante o pré-natal ou no período puerperal, tiveram menos dificuldades no aleitamento materno".

No presente estudo $64 \%$ das mães afirmaram conhecer os benefícios do aleitamento materno, mas este conhecimento é muito mais dos benefícios para o bebê que para a mãe. Tal fato pode ser observado na fala de três das puérperas entrevistadas: "O leite tem as proteínas que elas precisam. É um alimento completo" (P1), "É um alimento natural e por isso corre menos risco de fazer mal" (P2) e "Prevenção de algumas doenças para a neném" (P3). Discursos semelhantes foram encontrados no estudo de Junges et al (2010) e Simões (2013), que afirma "As puérperas entrevistadas se consideram bem informadas, porém não sabem todos os benefícios deste ato, sobretudo em se tratando da saúde da mulher, sendo necessário investir em maiores orientações [...], para maior motivação das mães. "Estes conhecimentos também refletem no tempo de aleitamento julgado necessário pelas mães; no presente estudo 37 das 50 mães entrevistadas disseram que o Aleitamento Materno Exclusivo deve ser mantido até o 6으 mês de vida, sendo que 62,16\% delas alegaram saber da importância do aleitamento materno.Esta pesquisa observou que a principal dificuldade relatada pelas puérperas foi a não apojadura do leite (28\%), tanto isoladamente quanto associada a outras dificuldades como à dificuldade na pega e ao mamilo plano, por exemplo. Em segundo lugar como dificuldade mais encontrada estão os mamilos invertidos bilateralmente (12\%) e em terceiro a fissura mamilar $(8 \%)$ e a dificuldade de sucção (8\%). Isto difere do encontrado por Marques et al (2008) em trabalho realizado na mesma instituição onde foi realizada esta pesquisa, mas com mães adolescentes, em que a dificuldade na pega/posição foi a mais prevalente $(38,1 \%)$, seguida de fissuras mamilares $(34,9 \%)$; problema com a pega também foi a dificuldade mais encontrada $(70,5 \%)$ no estudo de Rocci e Fernandes (2014) com puérperas atendidas em Hospital Amigo da Criança (HAC) na zona leste de São Paulo. Isto ocorre pela diversidade das populações estudas (com suas variações etárias, temporais e culturais, entre outras) que interferem em suas vivências em relação ao aleitamento materno e as instruções recebidas durante o pré-natal. Como já exposto neste trabalho estes são fatores que influenciam nas dificuldades encontradas pelas puérperas.

As dificuldades no aleitamento materno, como já exposto, podem ocorrer por motivos passíveis de prevenção e outros não; quando elas acontecem a família ou os amigos podem auxiliar em sua resolução, como tranquilizar a mãe no caso da demora na apojadura do leite, ou ser necessário a intervenção de um profissional de saúde. Porém, há situações que exigem um apoio mais específico que consiga atender às necessidades do binômio mãe/bebê, como os Bancos de Leite Humano (BLH).

Os bancos de leite podem auxiliar no processo de aleitamento materno orientando as mães quanto à pega adequada, ensinar a técnica de ordenha manual para retirada do leite, suprir as necessidades alimentares do neonato oferecendo leite humano ou complemento com fórmula infantil, entre outros suportes.

A fundação Santa Casa de Misericórdia do Pará conta com um banco de leite humano responsável por mais de 600 atendimentos por ano, entre mães que apresentam dificuldades e as impossibilitadas de amamentar. No presente estudo, $96 \%$ das puérperas estavam com dificuldades no momento da entrevista, mas $84 \%$ do total já tinha recebido apoio do banco de leite da instituição. Isso demonstra a ampla e rápida ação do banco de leite, que tão logo seja acionado, intervém segundo a necessidade das puérperas. Os profissionais do banco de leite são treinados para reconhecer e intervir nas dificuldades vividas no processo de aleitamento, oferecendo o suporte para garantir a nutrição do bebê e à assistência à puérpera.

No presente estudo as nutrizes receberam orientações quanto à pega e ordenha manual e/ou complemento, bem como orientações para situações específicas, cumprindo assim seu papel na promoção, proteção e apoio ao aleitamento materno (BRASIL, 2008, p. 19). A linguagem do profissional do BLH deve ser comprometida com a promoção do aleitamento materno e, em caso de dificuldades, na orientação sobre como e qual a importância de vencer os obstáculos que se interpõem à sua realização. Os Bancos de Leite, através de seus profissionais contribuem para que a nutriz fortaleça sua autoconfiança e autoestima, se planeje e tome decisões para enfrentar as dificuldades do processo de amamentar (BRANDÃO et al, 2012, p.357).

REAS/EJCH | Vol. 11 (5) | e292 | DOI: https://doi.org/10.25248/reas.e292.2019 Página 12 de 14 
Após as orientações recebidas pelos profissionais do BLH da Fundação Santa Casa do Pará a maioria das puérperas $(85,71 \%)$ se sentiu mais segura em relação ao processo de amamentação e ao enfretamento de suas dificuldades. A literatura apresenta estudos qualitativos que corroboram com este achado (RODRIGUES et al, 2013), permitindo afirmar que à assistência oferecida pelo BLH da Santa Casa foi satisfatória para a amostra avaliada no que tange o auxílio para puérperas com dificuldades no processo de amamentação.

\section{CONCLUSÃO}

O presente estudo demonstrou que a principal dificuldade no aleitamento materno encontrada foi a não apojadura do leite, seguida de mamilo invertido bilateralmente, fissura nos mamilos e dificuldade na sucção. A idade média das puérperas foi de 25,54 anos; a maioria era proveniente de zona urbana e residente na capital paraense, cursara o ensino médio, tinha companheiro, não planejara a presente gravidez, era primigesta, realizara pré-natal com 6 ou mais consultas e em algum momento fora conversado sobre amamentação. A maioria também tivera seus filhos por via cesariana, sendo a média de horas de vida dos neonatos no momento da pesquisa de 36,64 horas. Todas as pacientes entrevistadas pretendiam amamentar seus filhos da presente gestão, sendo que a maioria delas sabe da importância do aleitamento materno e acredita que ele pode se dar em regime exclusivo por no mínimo 6 meses. Dentre as não primigestas, a maioria amamentou seus filhos anteriores com dificuldades, sendo a não apojadura do leite a mais relata, mas mesmo assim ao amamenta-los afirmaram que o fizeram em caráter exclusivo por no mínimo 6 meses. Quase a totalidade das puérperas já tinham recebido auxílio do banco de leite no momento da pesquisa e a maior parte delas se sentiu segura após tal suporte.

\section{REFERÊNCIAS}

1. ALMEIDA JAG. Amamentação: um híbrido natureza-cultura [online]. Rio de Janeiro: Editora FIOCRUZ, 1999.120 p. ISBN: 978-85-85239-17-4.

2. ALMEIDA JM, LUZ SAB, UED FV. Apoio ao aleitamento materno pelos profissionais de saúde: revisão integrativa da literatura. Rev. paul. pediatr., São Paulo, v. 33, n. 3, p. 355-362, Sept. 2015.

3. Barreto CA, Silva LR, Christoffel MM. Aleitamento materno: a visão das puérperas. Rev. Eletr. Enf. [Internet]. 2009;11(3):60511.

4. Brandão EC, Silva GRF, Gouveia MTO, Soares LS. Caracterização da comunicação no aconselhamento em amamentação. Rev. Eletr. Enf. [Internet]. 2012 abr/jun;14(2):355-65.

5. BRANDÃO APM, ALMEIDA APR, SILVA LCB, et al. Aleitamento materno: fatores que influenciam o desmame precoce breastfeeding: factors affecting the early weaning Revista Científica FacMais, Volume V, Número 1. Ano 2016/1ํ Semestre. ISSN 2238-8427.

6. BRASIL. Ministério da Saúde. Federação Brasileira das Sociedades de Ginecologia e Obstetrícia - FEBRASGO. Associação Brasileira de Obstetras e Enfermeiras Obstetras - ABENFO. Parto, aborto e puerpério: assitência humanizada à mulher. Brasília: Ministério da Saúde, 2003.

7. BRASIL. Agência Nacional de Vigilância Sanitária. Banco de leite humano: funcionamento, prevenção e controle de riscos. Agência Nacional de Vigilância Sanitária. - Brasília: Anvisa, 2008. 160 p.

8. BRASIL. Ministério da Saúde. Secretaria de Atenção à Saúde. Departamento de Ações Programáticas e Estratégicas. II Pesquisa de Prevalência de Aleitamento Materno nas Capitais Brasileiras e Distrito Federal / Ministério da Saúde, Secretaria de Atenção à Saúde, Departamento de Ações Programáticas e Estratégicas. - Brasília: Editora do Ministério da Saúde, 2009.

9. BRASIL. Ministério da Saúde. Secretaria de Atenção à Saúde. Departamento de Atenção Básica. Saúde da criança: nutrição infantil: aleitamento materno e alimentação complementar / Ministério da Saúde, Secretaria de Atenção à Saúde, Departamento de Atenção Básica. - Brasília: Editora do Ministério da Saúde, 2009. 112 p. : il. - (Série A. Normas e Manuais Técnicos) (Cadernos de Atenção Básica, n. 23)

10. BRASIL. Ministério da Saúde. Secretaria de Atenção à Saúde. Departamento de Atenção Básica. Atenção ao pré-natal de baixo risco / Ministério da Saúde. Secretaria de Atenção à Saúde. Departamento de Atenção Básica. - Brasília: Editora do Ministério da Saúde, 2012. 318 p.: il. - (Série A. Normas e Manuais Técnicos) (Cadernos de Atenção Básica, $n^{\circ} 32$ ).

11. CAETANO MC, ORTIZ TTO, SILVA SGL et al. Alimentação complementar: práticas inadequadas em lactentes. J. Pediatr. (Rio J.), Porto Alegre, v. 86, n. 3, June 2010.

12. CARMONELE L, WILHELM LA, SANTOS CC, et al. Dificuldades vividas no processo do aleitamento materno. Curso de Enfermagem da Universidade Federal de Santa Maria (UFSM), Santa Maria, RS, Brasil

13. CARVALHO ACO, SARAIVA ARB, GONÇALVES GAA, et al. Aleitamento materno: promovendo o cuidar no alojamento conjunto. REVRENE - Revista da Rede de Enfermagem do nordeste 2013; 14 (2): 241-51

14. DAMIAO JJ. Influência da escolaridade e do trabalho maternos no aleitamento materno exclusivo. Rev. bras. epidemiol., São Paulo, v. 11, n. 3, p. 442-452, Sept. 2008. 
15. DIEHL JP, ANTON MC. Fatores emocionais associados ao aleitamento materno exclusivo e sua interrupção precoce: um estudo qualitativo. Aletheia, Canoas, n. 34, p. 47-60, abr. 2011.

16. FALEIROS FTV, TREZZA EMC, CARANDINA L. Aleitamento materno: fatores de influência na sua decisão e duração. Revista de Nutrição, Campinas, v. 19, p.5, p. 623-630, set./out. 2006.

17. Fragoso APR, Fortes RC. Fatores associados à prática do aleitamento materno entre nutrizes de um hospital público do Distrito Federal J Health Sci Inst. 2011;29(2):114-8

18. GALVAO DG. Formação em aleitamento materno e suas repercussões na prática clínica. Rev. bras. enferm., Brasília, v. 64, n. 2, p. 308-314, Apr. 2011.

19. GIUGLIANI ERJ. Problemas comuns na lactação e seu manejo. J. Pediatr. (Rio J.), Porto Alegre, v. 80, n. 5, supl. p. s147s154, nov. 2004.

20. JUNGES CF, RESSEL LB, BUDÓ MLD, et al. Percepções de puérperas quanto aos fatores que influenciam o aleitamento materno. Rev. Gaúcha Enferm. (Online), Porto Alegre, v. 31, n. 2, p. 343-350, June 2010.

21. LEVY L, BÉRTOLO H. Manual de Aleitamento Materno edição revista 2012. Lisboa: Comité Português para a UNICEF/Comissão Nacional Iniciativa Hospitais Amigos dos Bebés. Lisboa, 2012.

22. MARQUES RFSV, CUNHA ICC, ARAGÓN MG, et al. Fatores relacionados às dificuldades no aleitamento materno Entre mães adolescentes da fundação santa casa de misericórdia do Pará. Revista Paraense de medicina V.22 (1) janeiro a março 2008.

23. MEIRELLES CAB, OLIVEIRA MIC, MELLO RR, et al. Justificativas para uso de suplemento em recém-nascidos de baixo risco de um Hospital Amigo da Criança. Cad. Saúde Pública, Rio de Janeiro, v. 24, n. 9, p. 2001-2012, Sept. 2008.

24. MOY RJ. Prevalence, consequences and prevention of childhood nutritional iron deficiency: a child public health perspective. Clin Lab Haematol. 2006; 28:291-8

25. OLIVEIRA KMP, MARQUES IR. Situação do aleitamento materno no Brasil: uma revisão. Rev Enferm UNISA. 2011; 12(1): 73 78.

26. REA, M. F. Reflexões sobre a amamentação no Brasil: de como passamos a 10 meses de duração. Cad Saúde Pública 2003; 19 (Supl. 1): 37-45.

27. ROCCI E, FERNANDES FAQ. Dificuldades no aleitamento materno e influência no desmame precoce. Rev. Bras. Enferm. 2014 jan-fev; 67(1): 22-27.

28. ROCCI E, QUINTELLA FERNANDES RA. Dificuldades no aleitamento materno e influência no desmame precoce Revista Brasileira de Enfermagem, vol. 67, núm. 1, enero-febrero, 2014, pp. 22-27. Associação Brasileira de Enfermagem. Brasília, Brasil.

29. RODRIGUES DP, CONCEIÇÃO CS, ALVES VH et al. QUALIDADE ASSISTENCIAL DO BANCO DE LEITE HUMANO: PERCEPÇÃO DE USUÁRIAS. Rev enferm UFPE on line., Recife, 7(5):1271-1278, maio., 2013.

30. RODRIGUES NA, GOMES ACG. Aleitamento Materno: Fatores Determinantes do Desmamae Precoce. Enfermagem Revista, v. 17, n. 1 , p. $30-48,2014$

31. ROIG AO, MARTÍNEZ MR, GARCIA JC, et al. Fatores associados ao abandono do aleitamento materno durante os primeiros seis meses de vida. Rev. Latino-Am. Enfermagem, Ribeirão Preto, v. 18, n. 3, p. 373-380, jun. 2010.

32. SILVA WF, GUEDES ZCF. Tempo de aleitamento materno exclusivo em recém-nascidos prematuros e a termo. Rev. CEFAC, São Paulo, v. 15, n. 1, p. 160-171, Feb. 2013.

33. SIMÕES RFM. Universidade Estadual da Paraíba: Identificação Imediata das Dificuldades do Aleitamento Materno de um Hospital Público de Campina Grande, PB. 2013. 36 f. Trabalho de Conclusão de Curso (Graduação em Fisioterapia) Universidade Estadual da Paraíba, Centro de Ciências Biológicas e da Saúde, 2013.

34. VIEIRA GO, MARTINS CC, VIEIRA TO, et al. Fatores preditivos da interrupção do aleitamento materno exclusivo no primeiro mês de lactação. J. Pediatr. (Rio J.), Porto Alegre, v. 86, n. 5, p. 441-444, Oct. 2010.

35. VIELLAS EF, DOMINGUES RMSM, DIAS MAB, et al. Assistência pré-natal no Brasil. Cad. Saúde Pública, Rio de Janeiro, v. 30, supl. 1, p. S85-S100, 2014.

36. VOLPINI CCA, MOURA EC. Determinantes do desmame precoce no distrito noroeste de Campinas. Rev. Nutr 2005; $18(3): 311$ 9.

37. World Health Organization. Infant and young child nutrition: global strategy on infant and young child feeding. The optimal durantion of exclusive breastfeeding. Geneva: World Health Organization; 2001.

38. ZORZI NT, BONILHA ALL. Práticas utilizadas pelas puérperas nos problemas mamários. Rev. Bras. Enferm. Passo Fundo (RS), v. 59, n. 4, p. 521- 526, 2006. 